\title{
Phenotypic characteristics of human type II alveolar epithelial cells suitable for antigen presentation to $\mathrm{T}$ lymphocytes
}

\author{
Véronique Corbière ${ }^{1}$, Violette Dirix ${ }^{1}$, Sarah Norrenberg ${ }^{2}$, Mattéo Cappello ${ }^{3}$, Myriam Remmelink ${ }^{2}$, Françoise Mascart ${ }^{1,4^{*}}$
}

\begin{abstract}
Background: Type II alveolar epithelial cells (AECII) are well known for their role in the innate immune system. More recently, it was proposed that they could play a role in the antigen presentation to T lymphocytes but contradictory results have been published both concerning their surface expressed molecules and the $T$ lymphocyte responses in mixed lymphocyte cultures. The use of either AECll cell line or fresh cells could explain the observed discrepancies. Thus, this study aimed at defining the most relevant model of accessory antigen presenting cells by carefully comparing the two models for their expression of surface molecules necessary for efficient antigen presentation.

Methods: We have compared by flow cytometry the surface expression of the major markers involved in the immunological synapse on the A549 cell line, the most popular model of type II alveolar epithelial cells, and freshly isolated cells. HLA-DR, CD80, CD86, ICOS-L, CD54, CD58 surface expression were studied in resting conditions as well as after IFN- $\gamma / T N F-\alpha$ treatment, two inflammatory cytokines, known to modulate some of these markers.

Results: The major difference found between the two cells types was the very low surface expression of HLA-DR on the A549 cell line compared to its constitutive expression on freshly isolated AECII. The surface expression of co-stimulatory molecules from the B7 family was very low for the CD86 (B7-2) and ICOS-L (B7-H2) and absent for CD80 (B7-1) on both freshly isolated cells and A549 cell line. Neither IFN- $\gamma$ nor TNF- $\alpha$ could increase the expression of these classical co-stimulatory molecules. However CD54 (ICAM-1) and CD58 (LFA-3) adhesion molecules, known to be implicated in B7 independent co-stimulatory signals, were well expressed on the two cell types.
\end{abstract}

Conclusions: Constitutive expression of MHC class I and II molecules as well as alternative co-stimulatory molecules by freshly isolated AECII render these cells a good model to study antigen presentation.

\section{Background}

Type II alveolar epithelial cells (AECII) are since long recognized as important players of the innate immune system, secreting antimicrobial proteins like surfactant protein $\mathrm{A}, \mathrm{C}$ and $\mathrm{D}$, but also producing a variety of cytokines and chemokines [1-3]. Due to their location, they are exposed to microbes reaching the alveolus and can be infected by several infectious agents, such as influenza virus, severe acute respiratory syndrome-coronavirus, Legionella pneumophila, Bacillus anthracis or Mycobacterium tuberculosis which is well known to

\footnotetext{
* Correspondence: fmascart@ulb.ac.be

'Laboratory of Vaccinology and Mucosal Immunity, Université Libre de Bruxelles (U.L.B.), Brussels, Belgium

Full list of author information is available at the end of the article
}

multiply and to survive within AECII [4-10]. Indeed alveolar epithelial cells are being by far more numerous than the macrophages, the phagocytic cell prototype [11]. However besides the AECII, the alveolar surface is also covered by type I AEC but these cells mostly play a role for gaz exchange [12]. In contrast, cuboidal AECII were suggested to play a possible role of non-professional antigen-presenting cells as they were reported to express both class I and class II major histocompatibility complex molecules (MHC) [13]. Interestingly, AECII are in contact with a huge amount of lymphocytes, the cells involved in the development of specific immune responses. Indeed, the number of lymphocytes in the lung interstitium has been reported to be $10^{10}$, which is similar to the number of circulating lymphocytes [14]. 
Many studies turned therefore to a better characterization of the AECII phenotype and more precisely on the detection of surface molecules involved in antigenic presentation. As T-cell receptor engagement and co-stimulatory signals are usually required for the full activation of $\mathrm{T}$ cells, different authors have analyzed the expression of co-stimulatory molecules by AECII. However, several contradictory results were published, each paper focusing on a limited amount of phenotypic markers. Major differences between the results might be explained by technical differences between the studies [13,15-19]. In addition, most studies were performed on a human tumor cell line, the A549, defined as a model of human AECII [20], as freshly isolated AECII from human pulmonary pieces are rather difficult to obtain.

The aim of the study was to compare both models and to define the most suitable one to study antigen presentation. In this paper, we report a detailed phenotypic analysis of human AECII comparing the human tumor cell line A549 to freshly isolated human AECII. We have characterized the expression of MHC-class II molecules and the expression of different co-stimulatory molecules known to be involved in the immunological synapse, CD80, CD86, ICOS-L, CD40, CD54, CD58. The expression of these molecules was analyzed first on resting cells and then on cytokine-activated cells. To mimic inflammation, we chose to analyze the effect on the AECII phenotype of two major inflammatory cytokines, IFN- $\gamma$ and TNF- $\alpha$, known to modulate some of these surface molecules [17,21-26].

\section{Methods}

\section{A549 cell line culture}

A549, a human alveolar type II epithelial cell line from an adenocarcinoma (LGC Promochem, UK/ATCC ${ }^{\circledR}$; Number: CCL-185 ${ }^{\mathrm{TM}}$ ) was maintained in Dulbecco's modified Eagle's medium (DMEM, LONZA, Verviers, Belgium) supplemented with $10 \%$ heat-inactivated foetal calf serum (FCS, PAA Laboratories GmbH, Pashing, Austria) at $37^{\circ} \mathrm{C}$ in a $5 \% \mathrm{CO} 2$ atmosphere. For the experiments, the cell line was used from the $5^{\text {th }}$ to the $13^{\text {th }}$ passage.

\section{Human pulmonary type II alveolar epithelial cells}

After ethical committee agreement (Comité d'EthiqueHôpital Erasme, reference number P2007/175), AECII were isolated from macroscopically tumor free regions of lung tissues obtained following lobectomy or pneumectomy for lung cancer. The AECII isolation was adapted from a previously described technique [27]. After differential adherence of contaminating mononuclear cells, non-adherent AECII were plated at $5 \times 10^{5}$ cells/well in 48 wells flat-bottomed plates precoated with type I collagen (1\%) to obtain pure AECII [28]. Cells reached confluence after 24 or 48 hours.
The purity averaged $85.78 \%(81.78 \%-90.03 \%)$ (median, inter-quartile ranges) for the nine independent AECII isolations as assessed by flow cytometry (see below).

\section{Flow cytometry}

This technique was used to assess the purity of the cell suspensions and to characterize their phenotype after cytokine stimulation. Cells were first incubated for 30 minutes with FCS before staining to avoid non specific fixation of the antibodies.

To assess the purity of cell suspensions, cells were stained with antibodies directed to surface molecules not expressed by AECII: anti-human CD19-FITC (clone 4G7, mouse IgG1 kappa), CD45-PerCp (clone 2D1, mouse IgG1 kappa), CD11b-APC (clone D12, mouse IgG2a kappa), CD11c-APC (clone S-HCL-3, mouse IgG2b kappa) and CD14-APC (clone MphiP9, mouse IgG2b kappa). A goat polyclonal IgG anti-human DCLAMP-PE (CD208) was used to identify AECII in the cell suspension as DC-LAMP is constitutively expressed by AECII $[29,30]$. DC-LAMP staining was performed after fixation and permeabilization of the cells (lysing solution and permeabilization solution, BD Biosciences). All reagents were obtained from BD Biosciences (Erembodegem, Belgium), except the antibody to DC-LAMP which was from R\&D Systems Europe (Abingdon, UK).

To characterize the phenotype of the A549 cell line and of primary AECII, the cells were stained with antihuman antibodies to HLA-DR-PE (clone L243, mouse IgG2a kappa), CD80-PE (clone L307.4, mouse IgG1 kappa), CD86-PE (clone FUN-1, mouse IgG1 kappa), ICOS-L (clone 2D3/B7-H2, mouse IgG2b kappa), CD40FITC (clone 5C3, mouse IgG1 kappa), CD54-APC (clone HA58, mouse IgG1 kappa), CD58-FITC (clone $1 \mathrm{C} 3$, mouse IgG2a kappa). All the antibodies used were obtained from BD Biosciences.

Flow cytometric analysis was performed using a FACSCanto II (Becton Dickinson) and the FlowJo software (Tree Star, Ashland, OR, USA). Both the percentages of positive cells and the median of fluorescence intensity (MFI) were evaluated for each triplicate. For the MFI analysis, specific fluorescence intensity variations observed after activation were determined by the ratio between the MFIs of stimulated cells (MFIs) and resting cells (MFIr). As an increase in autofluorescence was observed during short-term cultures, the value obtained for non-labelled cells (MFIx 0) was subtracted from the MFI of the labelled cells (MFIx), for both resting and stimulating cells (MFIr and MFIs): (MFIs MFIs 0)/(MFIr - MFI r 0)

\section{Cytokine stimulations}

Cells were plated in 48 wells flat-bottomed plates (A549: $5 \times 10^{4}$ cells/well; AECII: $5 \times 10^{5}$ cells/well), and 
incubated until confluence (A549: 22 hours; AECII: 24/ 48 hours). In parallel to resting conditions, the cells were in vitro stimulated with human recombinant IFN- $\gamma$ (100 ng/ml), human recombinant TNF- $\alpha(50 \mathrm{ng} / \mathrm{ml})$ or a combination of the two cytokines (IFN- $\gamma 50 \mathrm{ng} / \mathrm{ml}$ and TNF- $\alpha 25 \mathrm{ng} / \mathrm{ml}$ ) (R\&D Systems Europe) during 24 hours before analyzing their phenotype by flow cytometry. Seven and four independent experiments were performed in triplicate for A549 cell line and AECII respectively.

\section{Statistics}

Results are presented as mean values obtained from triplicate and medians were used to compare groups. The non-parametric Mann-Whitney test was applied to compare phenotypic markers expression of A549 versus AECII in resting conditions. To compare the percentages of positive cells after cytokine stimulations versus resting conditions, the non-parametric Kruskal-Wallis test combined with the Dunn's multiple comparison test was used. The non-parametric Kruskal-Wallis test associated with the Dunn's multiple comparison test was used to compare MFI after stimulating conditions versus resting condition. A value of $P<0.05$ was considered to be significant. All results were obtained with the GraphPad Prism version 4.00 for Windows (GraphPad Software, San Diego, CA, USA, http://www.graphpad.com).

\section{Results}

Phenotypic characterization of freshly isolated type II AEC compared to the A549 cell line

Type II AEC isolated from human lung cultured until confluence were stained with phenotypic markers and compared to the A549 cell line, often used as a model of human AECII. The cells were stained with anti-human antibodies to HLA-DR, as it is the most strongly expressed class II locus. Whereas a high proportion of freshly isolated AECII expressed at their surface HLA-DR molecules (median $75.44 \%$, ranges: $68.73 \%-84.68 \%$ ), only a minority of A549 cells did express this marker (11.40\%, 0.03\% $16.60 \%)$, resulting in significant differences in the expression of MHC class II molecules between the two types of cell suspensions $(P<0.01)$ (Figure 1 ).

Analysis of the expression of the co-stimulatory molecules from the B7 family indicated that few cells of both suspensions express these markers. The study of the fresh AECII showed almost no expression of CD80 (7.22\%, 4.26\% - 10.14\%), a low expression of CD86

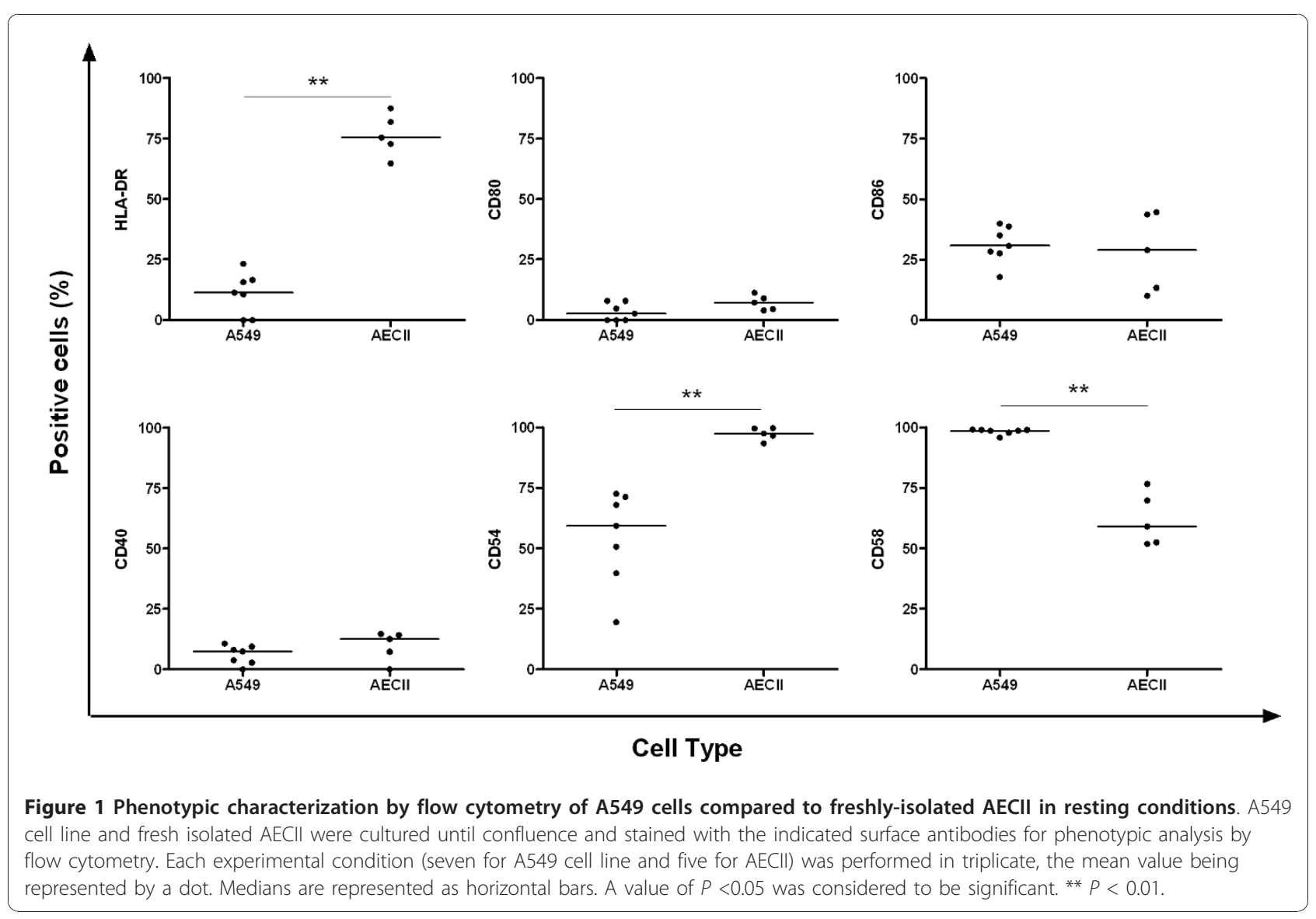


(28.93\%, $11.74 \%-44.13 \%)$ and of ICOS-L (14.82\%, $8.32 \%-16.76 \%)$. Similar results were obtained for the cell line A549 (Figure 1 and data not shown for ICOSL). The CD40 molecule was expressed only on a very low proportion of epithelial cells, respectively on $12.54 \%$ of the AECII $(3.66 \%-14.41 \%)$ and on $7.37 \%$ of the A549 cells (2.75\% - 9.43\%) (Figure 1$)$.

In contrast, two other co-stimulatory molecules were expressed on the surface from most cells of both A549 cell line and fresh AECII. CD54 was expressed on nearly all the freshly isolated type II AEC (97.37\%, 94.88\% - 99.55\%) and on an important proportion of A549 cells (59.21\%, $39.68 \%-71.21 \%$ ), with however significant differences in the proportions of positive cells within the cell suspensions $(P<0.01)$ (Figure 1). Conversely, CD58 was expressed on nearly all the A549 cells (98.54\%, 97.70\% - 98.89\%) and on a lower percentage of freshly isolated cells $(58.99 \%, 52.07 \%$ - 73.23\%) $(P<0.01)$ (Figure 1).

These results indicate the constitutive surface expression of HLA-DR on freshly isolated AECII and the low expression of this molecule on the A549 cell line. The presence of alternative co-stimulatory molecules was highlighted for the two cell suspensions, as well as the very low or even absent expression of the B7 family molecules.

\section{Modulation of A549 phenotypic markers expression with inflammatory cytokines}

In the course of a pulmonary infection, alveolar epithelial cells will be exposed to different inflammatory cytokines released by cells involved in the innate immunity that could modulate the expression of phenotypic markers. We therefore analyzed the expression of these markers in A549 cell line in presence of IFN- $\gamma$ and/or TNF- $\alpha$.

The results illustrated on Figure 2 are expressed as percentages of positive cells and as a ratio between the MFI obtained under stimulating conditions and those obtained on resting cells (Figure 3). The percentages of HLA-DR-expressing cells as well as the HLA-DR and

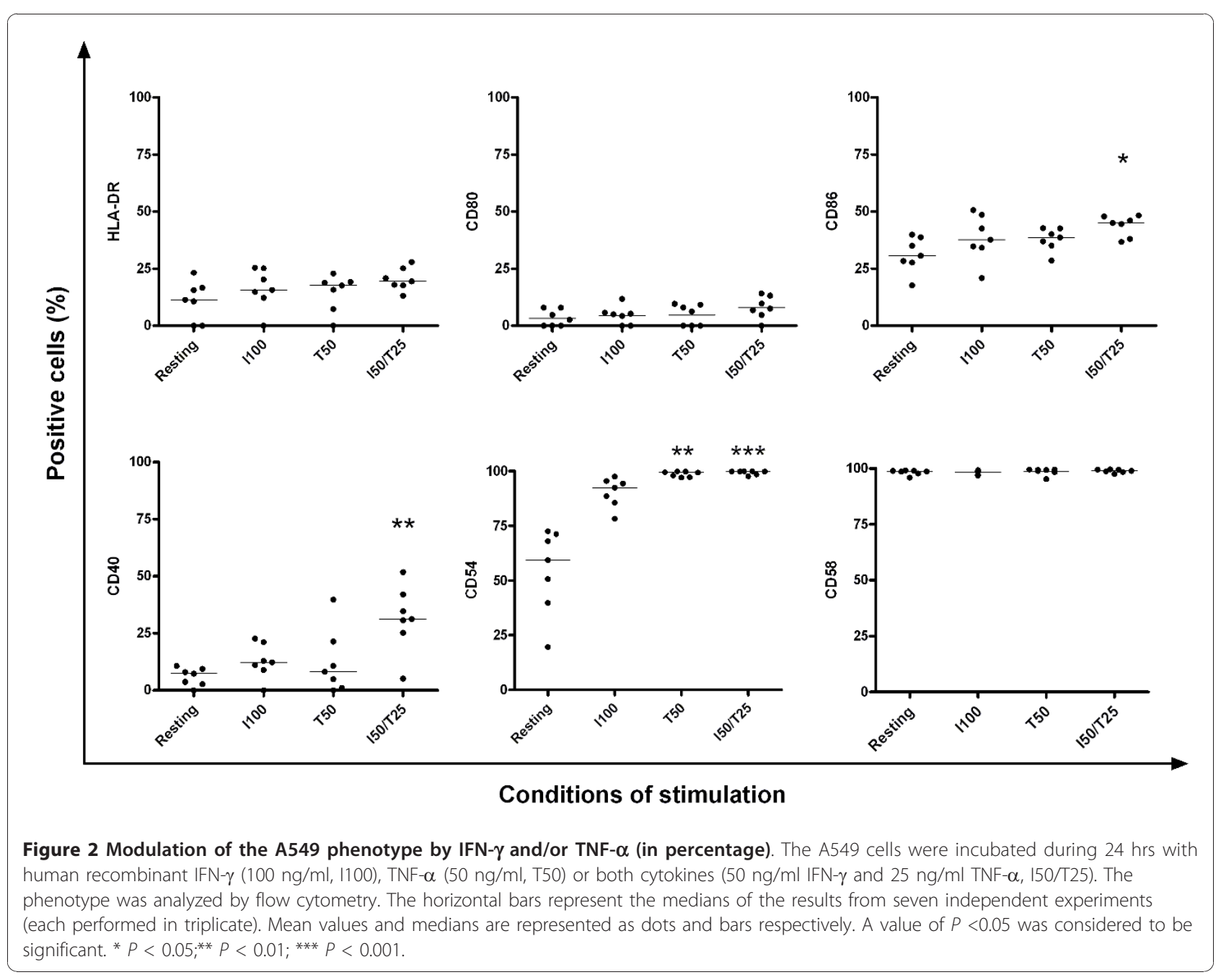




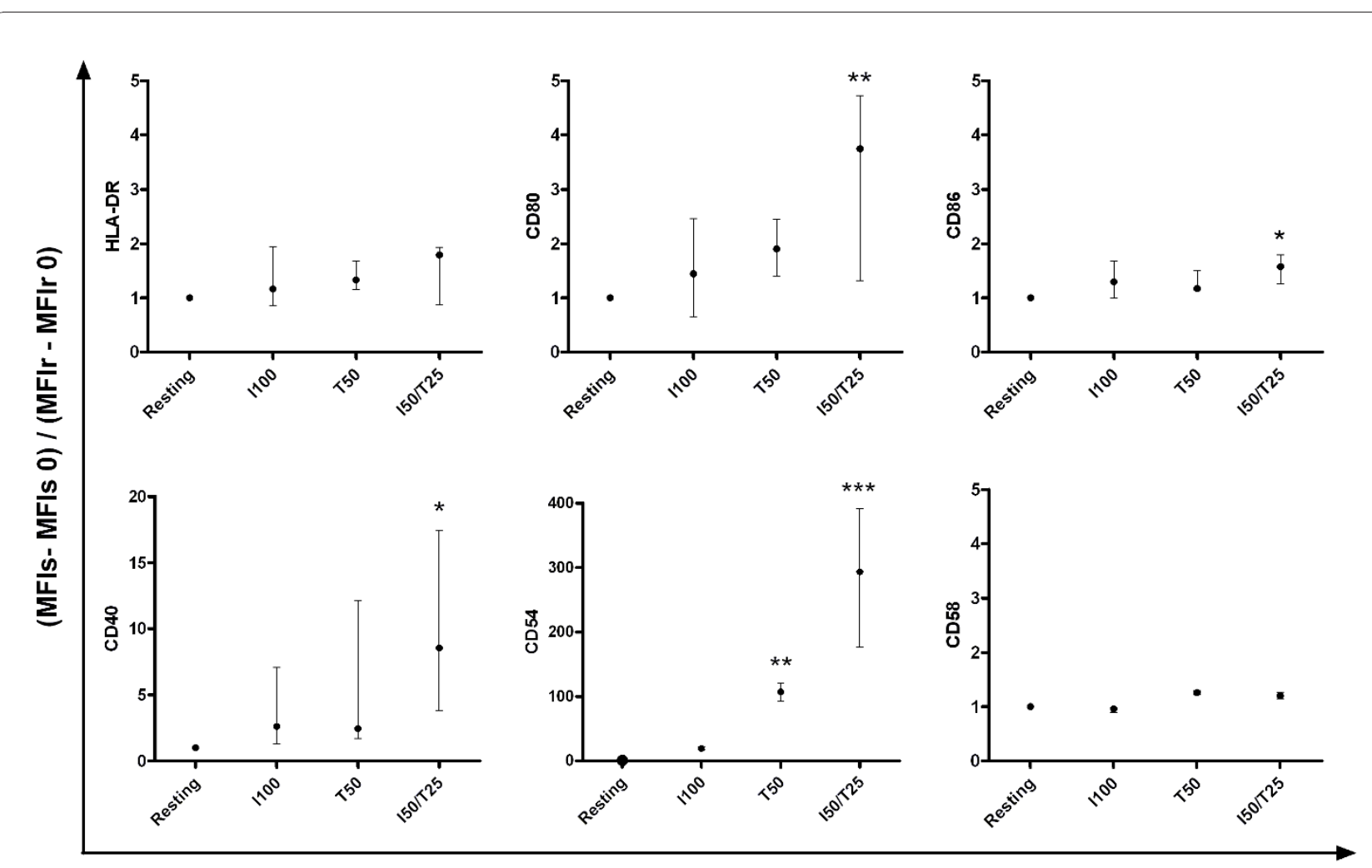

\section{Conditions of stimulation}

Figure 3 Modulation of the phenotypic markers density of A549 by inflammatory cytokines. These results were obtained from the same samples as those presented in Figure 2 but relative medians of fluorescence intensity (MFI) were analyzed. Results are represented by the medians and the inter-quartile ranges obtained for seven independent experiments. A value of $P<0.05$ was considered to be significant. ${ }^{*} P<$ 0.05 ; ${ }^{* *} P<0.01$; ${ }^{* * *} P<0.001$. I100: IFN- $\gamma 100 \mathrm{ng} / \mathrm{ml} ;$ T50: TNF- $\alpha 50 \mathrm{ng} / \mathrm{ml} ; 150 / \mathrm{T} 25:$ IFN- $\gamma 100 \mathrm{ng} / \mathrm{ml}$, TNF- $\alpha 25 \mathrm{ng} / \mathrm{ml}$.

CD58 MFIs did not change after stimulation with IFN- $\gamma$ and/or TNF- $\alpha$. In contrast, both the proportion of CD54-positive cells and the CD54-MFI were significantly higher in the presence of TNF- $\alpha(P<0.01)$ and when the cells were cultured with the combination of IFN- $\gamma$ and TNF- $\alpha(P<0.001)$. The percentage of cells expressing CD80 was not induced by cytokine stimulations, only some increase of the CD80-MFI was noted in the presence of the combination of IFN $-\gamma$ and TNF- $\alpha$ $(P<0.01)$. Finally, the combined stimulation with IFN- $\gamma$ and TNF- $\alpha$ increased both the proportion of CD86 and CD40-positive cells and the MFI of these molecules $(P<$ 0.05 for CD86 positive cells and CD86 MFI; and $P<$ 0.01 and $P<0.05$ for CD40 positive cells and CD40 MFI respectively).

\section{Modulation of fresh human AECII phenotypic markers expression with inflammatory cytokines}

The effect of IFN- $\gamma$ and/or TNF- $\alpha$ on the expression of phenotypic markers were also evaluated on freshly isolated AECII as phenotypic differences were observed compared to the A549 cell line.
The percentages of type II AEC expressing HLA-DR or the different co-stimulatory molecules investigated here were not different after incubating the cells with IFN- $\gamma$ and/ or TNF- $\alpha$ when compared to the resting cells (Figure 4). In contrast, a slight but significant increase in the MFI of different phenotypic markers was observed in the presence of the inflammatory cytokines indicating that the density of the markers at the cell surface was higher even if the proportion of positive cells did not increase (Figure 5). Higher expression of HLA-DR was observed in the presence of IFN- $\gamma$ and the combination of cytokines $(P<0.05)$. Similarly, a significantly higher expression of CD54 was noted after incubation of the cells especially with both IFN- $\gamma$ and TNF- $\alpha(P<0.01)$. The combination of the two cytokines also induced a higher expression of CD40 $(P<0.05)$. No change was noted in the cell surface expression of CD80, CD86 and CD58 molecules, the last one being expressed at basal level by the majority of the cells.

These results on the increase in the expression of CD54 suggest a possible major implication of this molecule in the immunological synapse, without excluding a role for CD58 in co-stimulatory signal transduction. 

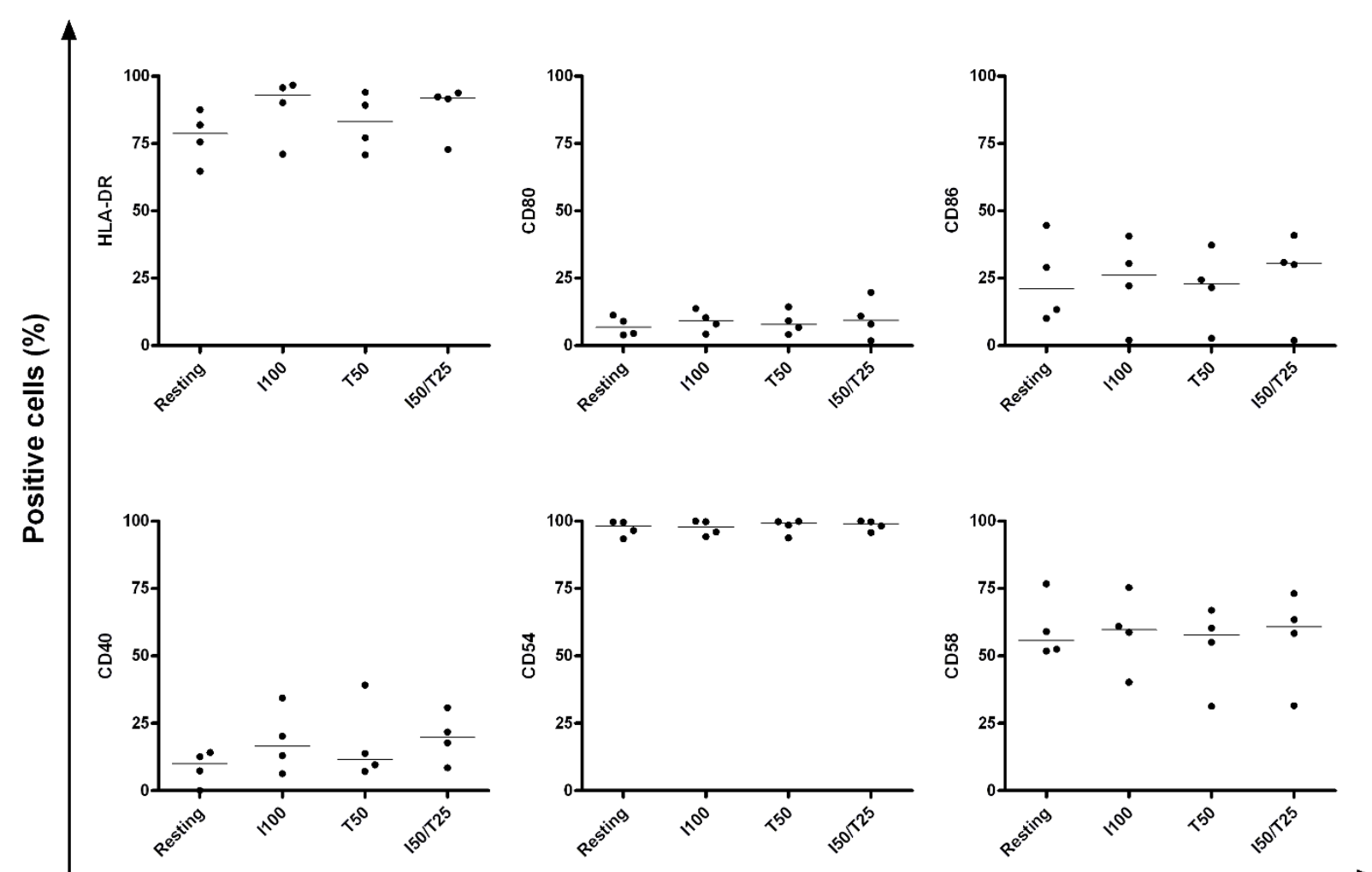

Conditions of stimulation

Figure 4 Modulation of fresh AECII phenotype by IFN- $\boldsymbol{\gamma}$ and/or TNF- $\boldsymbol{\alpha}$ (in percentage). AECll were treated as was A549 cell line in Figure 2. Four independent experiments were performed in triplicate, each point representing the mean value. The bars represent the medians. Results were compared to their resting conditions. I100: IFN- $\gamma 100 \mathrm{ng} / \mathrm{ml}$; T50: TNF- $\alpha 50 \mathrm{ng} / \mathrm{ml}$; 150/T25: IFN- $\gamma 100 \mathrm{ng} / \mathrm{ml}$, TNF- $\alpha 25 \mathrm{ng} / \mathrm{ml}$.

\section{Discussion}

If the role of AECII in the innate immune system is well recognized, their role as accessory antigen-presenting cells has been more recently proposed. However, until now different contradictory results have been published both concerning the surface-expressed molecules involved in antigen presentation and the in vitro $\mathrm{T}$ lymphocyte response to AECII-presented antigens [13,15-19,31,32]. We postulated that such differences could be due to the use of different cell types (cell line or not), and to the absence of standardization of the techniques used to analyze these markers. The expression of co-stimulatory molecules by AECII was first reported but recent papers claim that some markers are absent and could contribute to an unresponsiveness of T lymphocytes to AECII stimulation. However, as interstitial lung lymphocytes comprise as much $\mathrm{CD}^{+}$and $\mathrm{CD} 4^{+}$lymphocytes [Beukinga I, personal communication], we carefully compared here the classically used model of type II AEC, the A549 cell line, to freshly isolated AECII, for their surface expression of the major markers involved in the immunological synapse. As these surface molecules can be modulated by inflammatory molecules released during lung infections, we further analyzed the modulation of these markers expression by two major inflammatory cytokines, IFN- $\gamma$ and TNF- $\alpha[17,21-26]$. We adapted the protocol described by I.R. Witherden and T.D. Tetley for the isolation of AECII as the recommended enzymatic treatment with trypsin does not affect the expression of surface markers on AECII [13], in contrast to dispase sometimes used to isolate AECII and who degrades ICOS-L [18].

The expression of MHC-II molecules is mandatory for the antigen presentation to $\mathrm{CD}^{+}{ }^{+} \mathrm{T}$ lymphocytes and we confirmed that freshly isolated AECII have a high constitutive surface expression of HLA-DR molecules as described by Cunningham et al. [31] whereas the A549 cell line did not expressed the MHC-II molecules. The MHC-II molecules expression of the latest one was even not modulated by IFN- $\gamma$ and/or TNF- $\alpha$. These two last observations reinforce the data obtained by Redondo et al. who find a very low expression of MHC-II molecules by the A549 cell line with no modulation by IFN- $\gamma$ [21]. In contrast, we reported here that the constitutive MHC-II molecules expression by freshly isolated cells was significantly upregulated by IFN- $\gamma$ 


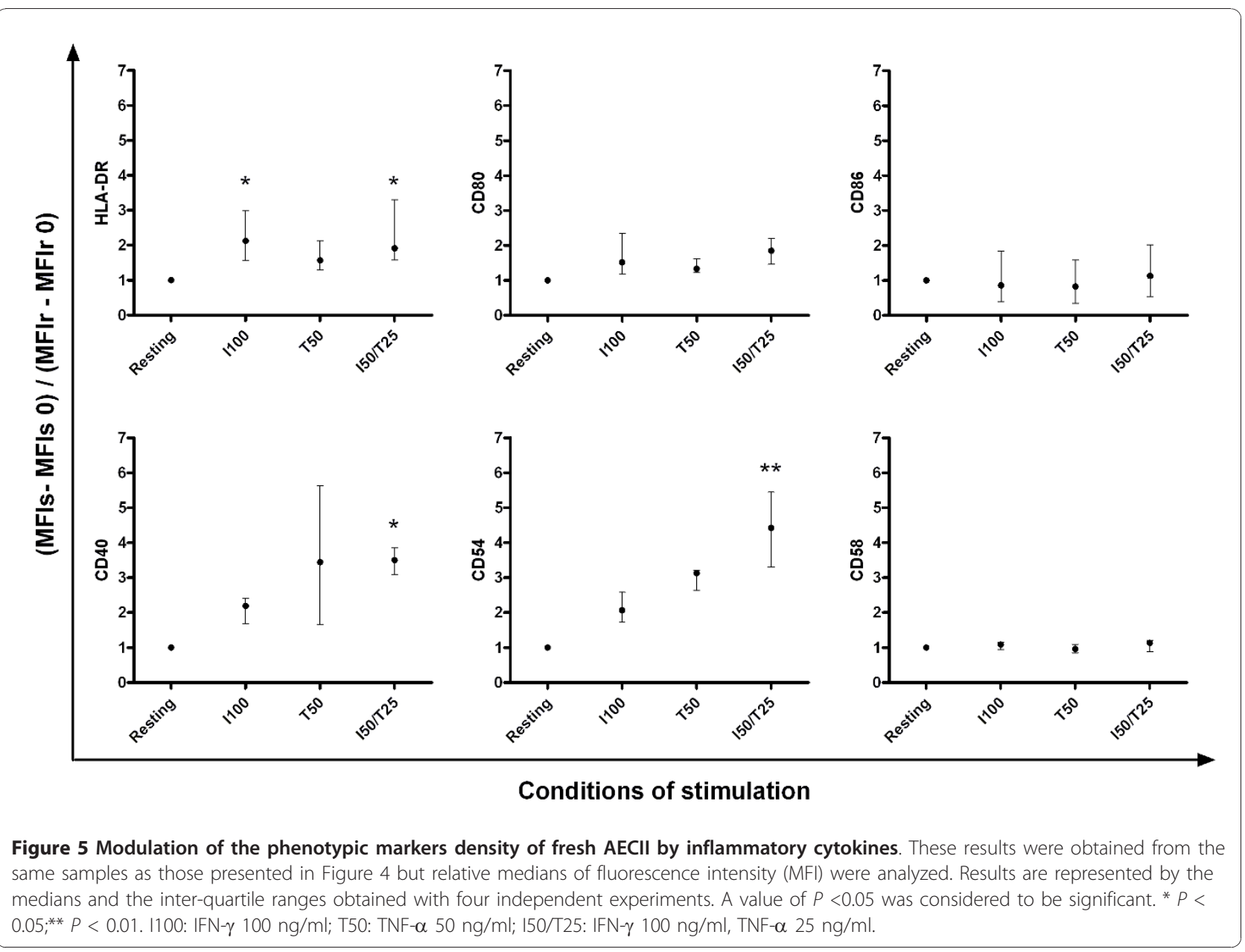

and TNF- $\alpha$, suggesting further the potential of these cells to present antigens to $\mathrm{CD} 4^{+} \mathrm{T}$ lymphocytes. These data differ from those reported by Debabbi et al. [17], most probably as a consequence of differences in the set up analysis used. Indeed, as stressed in the Material and Methods section, we subtracted the auto-fluorescence of non-stained cells before comparing the MFI from stimulating and resting cells to take into account the observed MFI increase of the resting cells, probably secondary to morphological changes.

In addition to the expression of $\mathrm{MHC}$ molecules, antigen presentation to lymphocytes usually needs co-stimulatory signals. The most powerful one is given by the B7/CD28 interaction [33]. In agreement with Cunningham et al., we showed here a lack of expression of CD80 (B7-1) and a low expression of CD86 (B7-2) both on the A549 cell line and on the freshly isolated AECII [31]. Only a slight increase in the densities of CD80 and CD86 and in the number of CD86 expressing cells on the A549 cell line was noted in the presence of IFN- $\gamma$ and TNF- $\alpha$. Another member of the B7 family, ICOS-L (B7-H2), has been described as playing a role in the activation of memory
T lymphocytes [34], but we did not confirm its previously reported expression on AECII [26]. Indeed, we found a very low expression of ICOS-L with no modulation, both on the A549 cell line and on the freshly isolated AECII (data not shown). Globally, these results indicate that B7 family molecules are expressed only at low level by AECII and that their surface expression is not strongly induced upon activation, as opposed to professional APC, such as activated dendritic cells or macrophages. Finally, the expression of CD40 was also shown to be low at the basal state on both cell types with however a slight but significant increase after stimulation with the combination of IFN- $\gamma$ and TNF- $\alpha$. Whether the increased expression of these molecules observed in both A549 and AECII, has an impact on the antigenic presentation need to be proved.

All these data suggest that AECII are probably not able to activate neither naive nor memory $\mathrm{T}$ lymphocytes by the classical pathway. However, alternative co-stimulatory signals have been reported allowing the stimulation in recall responses of $\mathrm{CD}_{4}^{+}$and $\mathrm{CD}^{+} \mathrm{T}$ lymphocytes in the absence of B7/CD28 interaction. This pathway involves the CD54/LFA-1 and/or CD58/CD2 interactions [35-37]. Both 
the A549 cell line and the freshly isolated AECII expressed CD54 and CD58 with a higher level of expression of CD54 and a lower expression of CD58 on the AECII compared to the A549 cell line. Even if no regulation of the expression of CD58 was observed after cytokines stimulation, its high basal expression suggests that this molecule could play a role in the immunological synapse and allow efficient lymphocyte activation as shown for endothelial cells [36]. In contrast, the expression of CD54 was highly upregulated after cytokines stimulation on both cell types. The role of these molecules when the B7/CD28 interaction is lacking was previously shown in a mouse model [35]. Therefore, we suggest that both CD58 and CD54 could play a major role in the antigenic presentation by AECII and that these cells could be able to present antigens to both $\mathrm{CD} 4^{+}$and $\mathrm{CD} 8^{+} \mathrm{T}$ lymphocytes.

\section{Conclusions}

A549 cell line is not suitable to analyze the antigen presentation to $\mathrm{CD}^{+} \mathrm{T}$ lymphocytes as it lacks the MHCII surface expression. However, as it kept the expression of MHC-I molecules, as well as the expression of CD54 and CD58, this cell line could be appropriate to study the interactions with $\mathrm{CD} 8^{+} \mathrm{T}$ lymphocytes. In contrast, freshly isolated AECII could play a role in the activation of both $\mathrm{CD}^{+}$and $\mathrm{CD}^{+}{ }^{+} \mathrm{T}$ lymphocytes as they expresses MHC-II and MHC-I molecules as well as alternative co-stimulatory CD54 and CD58.

\section{Acknowledgements}

The authors thank Prof. T.D. Tetley for her availability and her precious help during AECII isolation set up. This work was supported by the European Commission within the $7^{\text {th }}$ Framework Program, grant agreement $n^{\circ} 200732$.

\section{Author details}

'Laboratory of Vaccinology and Mucosal Immunity, Université Libre de Bruxelles (U.L.B.), Brussels, Belgium. 'Laboratory of Pathology, Hôpital Erasme, Université Libre de Bruxelles, Brussels, Belgium. ${ }^{3}$ Department of Thoracic Surgery, Hôpital Erasme, Université Libre de Bruxelles, Brussels, Belgium. ${ }^{4}$ Immunobiology Clinic, Hôpital Erasme, Université Libre de Bruxelles, Brussels, Belgium.

\section{Authors' contributions}

VC made substantial contributions to the analysis and interpretation of the data, and wrote the manuscript. VD performed experiments, interpreted the results, and critically read the manuscript. SN, MR provided us with macroscopically tumor free regions of lung tissues obtained following lobectomy or pneumectomy for lung cancer performed by MC Thoracic Surgery department. FM planned the concept and study design, critically read and corrected the manuscript. All the authors have critically read the manuscript and approved its submission.

\section{Competing interests}

The authors declare that they have no competing interests.

Received: 14 September 2010 Accepted: 24 January 2011 Published: 24 January 2011

\section{References}

1. Fehrenbach H: Alveolar epithelial type II cell: defender of the alveolus revisited. Respir Res 2001, 2:33-46.
2. Holmskov U, Jensenius JC: Structure and function of collectins: humoral C-type lectins with collagenous regions. Behring Inst Mitt 1993, 93:224-235.

3. Lin Y, Zhang M, Barnes PF: Chemokine production by a human alveolar epithelial cell line in response to Mycobacterium tuberculosis. Infect Immun 1998, 66:1121-1126.

4. Nakajima N, Hata S, Sato Y, Tobiume M, Katano H, Kaneko K, Nagata N, Kataoka M, Ainai A, Hasegawa H, Tashiro M, Kuroda M, Odai T, Urasawa N, Ogino T, Hanaoka H, Watanabe M, Sata T: The first autopsy case of pandemic influenza (A/H1N1pdm) virus infection in Japan: detection of a high copy number of the virus in type II alveolar epithelial cells by pathological and virological examination. Jpn J Infect Dis 2010, 63:67-71.

5. Guo Y, Korteweg C, McNutt MA, Gu J: Pathogenetic mechanisms of severe acute respiratory syndrome. Virus Res 2008, 133:4-12.

6. Molmeret M, Bitar DM, Han L, Kwaik YA: Cell biology of the intracellular infection by Legionella pneumophila. Microbes Infect 2004, 6:129-139.

7. Bermudez LE, Goodman J: Mycobacterium tuberculosis invades and replicates within type II alveolar cells. Infect Immun 1996, 64:1400-1406.

8. Russell B, Vasan R, Keene D, Koehler T, Xu Y: Potential dissemination of Bacillus anthracis utilizing human lung epithelial cells. Cell Microbiol 2008, 10(4):945-957.

9. Mehta PK, King CH, White EH, Murtagh JJ Jr, Quinn FD: Comparison of in vitro models for the study of Mycobacterium tuberculosis invasion and intracellular replication. Infect Immun 1996, 64:2673-2679.

10. Hernández-Pando $R$, Jeyanathan M, Mengistu G, Aguilar D, Orozco H, Harboe M, Rook GA, Bjune G: Persistence of DNA from Mycobacterium tuberculosis in superficially normal lung tissue during latent infection. Lancet 2000, 356:2133-2138.

11. Bermudez LE, Sangari FJ, Kolonoski P, Petrofsky M, Goodman J: The efficiency of the translocation of Mycobacterium tuberculosis across a bilayer of epithelial and endothelial cells as a model of the alveolar wall is a consequence of transport within mononuclear phagocytes and invasion of alveolar epithelial cells. Infect Immun 2002, 70:140-146.

12. Herzog EL, Brody AR, Colby TV, Mason R, Williams MC: Knowns and unknowns of the alveolus. Proc Am Thorac Soc 2008, 5:778-782.

13. Cunningham AC, Milne DS, Wilkes J, Dark JH, Tetley TD, Kirby JA: Constitutive expression of MHC and adhesion molecules by alveolar epithelial cells (type II pneumocytes) isolated from human lung and comparison with immunocytochemical findings. J Cell Sci 1994, 107:443-449.

14. Krug $N$, Tschernig $T$, Holgate $S$, Pabst R: How do lymphocytes get into the asthmatic airways? Lymphocyte traffic into and within the lung in asthma. Clin Exp Allergy 1998, 28:10-18.

15. Salik E, Tyorkin M, Mohan S, George I, Becker K, Oei E, Kalb T, Sperbe K: Antigen trafficking and accessory cell function in respiratory epithelial cells. Am J Respir Cell Mol Biol 1999, 21:365-379.

16. Oei E, Kalb T, Beuria P, Allez M, Nakazawa A, Azuma M, Timony M, Stuart Z, Chen H, Sperber K: Accessory cell function of airway epithelial cells. Am J Physiol Lung Cell Mol Physiol 2004, 287:318-331.

17. Debbabi H, Ghosh S, Kamath AB, Alt J, Demello DE, Dunsmore S, Behar SM: Primary type II alveolar epithelial cells present microbial antigens to antigen-specific CD4+ T cells. Am J Physiol Lung Cell Mol Physiol 2005, 289:274-279.

18. Lo B, Hansen S, Evans K, Heath JK, Wright JR: Alveolar epithelial type II cells induce T cell tolerance to specific antigen. J Immunol 2008, 180:881-888.

19. Sato K, Shimizu T, Sano C, Tomioka H: Effects of type II alveolar epithelial cells on T cell mitogenic responses to concanavalin $\mathrm{A}$ and purified protein derivatives. Microbiol Immunol 2005, 49:885-890.

20. Lieber M, Smith B, Szakal A, Nelson-Rees W, Todaro G: A continuous tumor-cell line from a human lung carcinoma with properties of type II alveolar epithelial cells. Int J Cancer 1976, 17:62-70.

21. Redondo M, Ruiz-Cabello M, Concha A, Hortas ML, Serrano A, Morell M, Garrido F: Differential expression of MHC class II genes in lung tumour cell lines. Eur J Immunogenet 1998, 25:385-391.

22. Kvale D, Brandtzaeg P, Løvhaug D: Up-regulation of the expression of secretory component and HLA molecules in a human colonic cell line by tumour necrosis factor-alpha and gamma interferon. Scand I Immunol 1988, 28(3):351-357.

23. Kato M, Ohashi K, Saji F, Wakimoto A, Tanizawa O: Expression of HLA class I and beta 2-microglobulin on human choriocarcinoma cell lines: 
induction of HLA class I by interferon-gamma. Placenta 1991, 12(3):217-226.

24. Creery WD, Diaz-Mitoma F, Filion L, Kumar A: Differential modulation of B7-1 and B7-2 isoform expression on human monocytes by cytokines which influence the development of T helper cell phenotype. Eur J Immunol 1996, 26:1273-1277.

25. Cunningham AC, Kirby JA: Regulation and function of adhesion molecule expression by human alveolar epithelial cells. Immunology 1995, 86(2):279-286.

26. Qian X, Agematsu K, Freeman GJ, Tagawa Y, Sugane K, Hayashi T: The ICOS-ligand B7-H2, expressed on human type II alveolar epithelial cells, plays a role in the pulmonary host defense system. Eur J Immunol 2006, 36:906-918.

27. Witherden IR, Tetley TD, Rogers DF, Donnelly LE: Isolation and Culture of Human Alveolar Type II Pneumocytes. In Human airway inflammation: sampling techniques and analytical protocols. Edited by: Rogers DF and Donnelly LE. New Jersey: Humana Press Inc; 2001:137-146.

28. Witherden IR, Vanden Bon EJ, Goldstraw P, Ratcliffe C, Pastorino U, Tetley TD: Primary human alveolar type II epithelial cell chemokine release: effects of cigarette smoke and neutrophil elastase. Am J Respir Cell Mol Biol 2004, 30:500-509.

29. Salaun B, de Saint-Vis B, Pacheco N, Pacheco Y, Riesler A, Isaac S, Leroux C, Clair-Moninot V, Pin JJ, Griffith J, Treilleux I, Goddard S, Davoust J, Kleijmeer M, Lebecque S: CD208/dendritic cell-lysosomal associated membrane protein is a marker of normal and transformed type II pneumocytes. Am J Pathol 2004, 164:861-871.

30. Akasaki K, Nakamura N, Tsukui N, Yokota S, Murata S, Katoh R, Michihara A, Tsuji H, Marques ET Jr, August JT: Human dendritic cell lysosomeassociated membrane protein expressed in lung type II pneumocytes. Arch Biochem Biophys 2004, 425(2):147-57.

31. Cunningham AC, Zhang JG, Moy JV, Ali S, Kirby JA: A comparison of the antigen-presenting capabilities of class II MHC-expressing human lung epithelial and endothelial cells. Immunology 1997, 91:458-463.

32. Gereke M, Jung S, Buer J, Bruder D: Alveolar type II epithelial cells present antigen to CD4(+) T cells and induce Foxp3(+) regulatory T cells. Am J Respir Crit Care Med 2009, 179:344-355.

33. Van Gool SW, Vandenberghe P, de Boer M, Ceuppens JL: CD80, CD86 and CD40 provide accessory signals in a multiple-step T-cell activation model. Immunol Rev 1996, 153:47-83.

34. Ling V, Wu PW, Miyashiro JS, Marusic S, Finnerty HF, Collins M: Differential expression of inducible costimulator-ligand splice variants: lymphoid regulation of mouse GL50-B and human GL50 molecules. J Immunol 2001, 166:7300-7308.

35. Gaglia JL, Greenfield EA, Mattoo A, Sharpe AH, Freeman GJ, Kuchroo VK: Intercellular adhesion molecule 1 is critical for activation of CD28deficient T cells. J Immunol 2000, 165:6091-6098.

36. Rose ML: Endothelial cells as antigen-presenting cells: role in human transplant rejection. Cell Mol Life Sci 1998, 54:965-978.

37. Damle NK, Klussman K, Linsley PS, Aruffo A: Differential costimulatory effects of adhesion molecules B7, ICAM-1, LFA-3, and VCAM-1 on resting and antigen-primed CD4+ T lymphocytes. J Immunol 1992, 148:1985-1992.

\section{doi:10.1186/1465-9921-12-15}

Cite this article as: Corbière et al:: Phenotypic characteristics of human type II alveolar epithelial cells suitable for antigen presentation to $T$ lymphocytes. Respiratory Research 2011 12:15.

\section{Submit your next manuscript to BioMed Central and take full advantage of:}

- Convenient online submission

- Thorough peer review

- No space constraints or color figure charges

- Immediate publication on acceptance

- Inclusion in PubMed, CAS, Scopus and Google Scholar

- Research which is freely available for redistribution 